\title{
Defects of CTLA-4 Are Associated with Regulatory T Cells in Myasthenia Gravis Implicated by Intravenous Immunoglobulin Therapy
}

\author{
Wenhua Xu $\mathbb{D}^{1}{ }^{1}$ Mingshan Ren, ${ }^{1}$ Swagata Ghosh, ${ }^{2}$ Kai Qian, ${ }^{3}$ Zhaofeng Luo, ${ }^{4}$ Aimei Zhang, ${ }^{5}$ \\ Cuiping Zhang, ${ }^{5}$ and Jiajun Cui $\circledast^{3}$ \\ ${ }^{1}$ Department of Neurology, The First Affiliated Hospital of University of Science and Technology of China, Hefei, China \\ ${ }^{2}$ Department of Internal Medicine, Division of Infectious Diseases and International Health, University of Virginia, \\ Virginia 22908, USA \\ ${ }^{3}$ The Center for Translational Medicine, Yichun University, Yichun, China \\ ${ }^{4}$ Hefei National Laboratory for Physical Science, Core Facility Center for Life Sciences, University of Science and Technology of China, \\ Hefei, China \\ ${ }^{5}$ Central Laboratory, The First Affiliated Hospital of University of Science and Technology of China, Hefei, China
}

Correspondence should be addressed to Wenhua Xu; wenhuaxu1115@163.com and Jiajun Cui; cui_jj@hotmail.com

Received 24 October 2019; Accepted 24 January 2020; Published 14 February 2020

Academic Editor: Vera L. Petricevich

Copyright (C) 2020 Wenhua Xu et al. This is an open access article distributed under the Creative Commons Attribution License, which permits unrestricted use, distribution, and reproduction in any medium, provided the original work is properly cited.

\begin{abstract}
Myasthenia gravis (MG) is a $\mathrm{CD}^{+} \mathrm{T}$ cell-dependent autoimmune disease resulting from aberrant immune response mediated by circulating autoantibodies at the neuromuscular junction. Intravenous immunoglobulin (IVIg) is an expensive and commonly used immunotherapeutic approach to treat patients with MG. The mechanisms of actions involved in IVIg treatment, however, remain to be investigated. In an effort to examine the roles of various subsets of $\mathrm{CD}^{+} \mathrm{T}$ cells in the periphery blood of $\mathrm{MG}$ and uncover the mechanisms that contribute to the therapeutical effects of IVIg, we first demonstrated that a subset of CD4 ${ }^{+} \mathrm{T}$ cells, CTLA-4-expressing regulatory $\mathrm{T}$ (Treg) cells, were underrepresented and functionally defective in MG patients. The dynamic profiling during the IVIg therapy course further revealed an inverse relationship between the frequency of CTLA- $4^{+}$Treg and the quantitative MG (QMG) score that represents disease severity. Our mechanistic studies indicated that IVIg expands CTLA4-Treg cells via modulating antigen-presenting dendritic cells (DCs). To determine the molecular defects of CTLA-4 in abnormities of Treg in MG patients, we demonstrated hypermethylation at -658 and -793 CpGs of CTLA-4 promoter in MG Tregs. Interestingly, IVIg therapy significantly reduced the methylation level at these two sites in MG patients. Overall, our study may suggest a role of CTLA-4 in functionally defected Treg cells in MG and its actions involved in IVIg therapy.
\end{abstract}

\section{Introduction}

Myasthenia gravis (MG) is an autoimmune disorder characterized by varying degrees of muscle weakness and fatigue. It is mainly caused by autoantibodies against the postsynaptic acetylcholine receptors (AChRs) at the neuromuscular junction [1-3]. The synthesis of the pathogenic anti-AChR antibodies, which are primarily high-affinity IgG, requires the elicitation and intervention of $\mathrm{CD}^{+} \mathrm{T}$ cells, also called effector $\mathrm{T}$ cells (Teff), and their associated cytokines [4-6].
$\mathrm{CD}^{+} \mathrm{T}$ cells play central roles in the adaptive immune system. Naïve $\mathrm{CD} 4^{+} \mathrm{T}$ cells after being activated can be differentiated into a range of distinct lineages based on cytokine secretion patterns, including classical Th1 and Th2 cells, the more recently identified Th17 cells, follicular helper $\mathrm{T}$ (Tfh) cells, and regulatory $\mathrm{T}$ (Treg) cells [7-9]. Those $\mathrm{CD}^{+} \mathrm{T}$ cell subsets have been implicated in the development of a number of autoimmune diseases including MG [10-12]. IFN- $\gamma$-producing Th 1 cells have been shown to be involved in the pathogenesis of many organ-specific autoimmune diseases [13]. Both Th1 and Th2 cells have been reported to be correlated 
TABLE 1: The clinical characteristics of MG patients.

\begin{tabular}{lcccc}
\hline MGFA class & Number & Age $($ mean \pm SD $)$ & Male/female & IVIg therapy \\
\hline I & 9 & $39.33 \pm 11.24$ & $4 / 5$ & 0 \\
II & 16 & $37.47 \pm 15.21$ & $3 / 13$ & 6 \\
III & 9 & $43.33 \pm 15.46$ & $5 / 4$ & 9 \\
IV & 5 & $45.60 \pm 11.06$ & $1 / 4$ & 5 \\
Total & 39 & $39.34 \pm 14.37$ & $13 / 26$ & 20 \\
\hline
\end{tabular}

with clinical signs of induced experimental autoimmune myasthenia gravis (EAMG) $[14,15]$. The alterations of Th17 cells and their related cytokines, IL-17 and TGF- $\beta 1$, have been observed in MG patients with thymomas [16]. Tfh cells provide help to B cells in germinal center and have been shown to exhibit an enhanced expression in the thymoma related to the clinical severity of $M G[17,18]$. As the major regulator of $\mathrm{T}$ cell-mediated immunity, regulatory $\mathrm{CD}^{+} \mathrm{T}$ (Treg) cells express forkhead box P3 (FOXP3) transcription factor and suppress aberrant immune responses that result in autoimmune disorders [19-21]. Defects in FOXp $^{+}$Treg cells have been shown to contribute to the development of MG and EAMG by us and many others $[16,22-26]$.

Although FOXp3 has been proposed as the master regulator that controls the suppressive function of Treg cells, a significant percentage of human-activated FOXp3expressing $\mathrm{T}$ cells do not possess regulatory function, suggesting that other factors may operate concurrently with FOXp3 to mediate Treg function [27-30]. One of the candidate regulators is cytotoxic T lymphocyte-associated antigen4 (CTLA-4). CTLA-4 is an inhibitory costimulatory factor constitutively expressed in a large portion of FOXp $3^{+}$Treg cells and has been shown to be critical to their suppressive function [31-33]. The aberrant expression of CTLA-4 has been observed in MG patients in a number of studies [34, 35]. However, whether the abnormalities of CTLA-4 contribute to Treg defects in MG and the role of CTLA-4 in the pathogenesis of $\mathrm{MG}$ are underappreciated.

Intravenous immunoglobulin (IVIg), a therapeutic preparation of pooled human polyclonal IgG, is a costly and frequently used immunomodulation therapy for patients with autoimmune and inflammatory diseases [36, 37]. Although IVIg therapy has been used for three decades, the mechanisms by which it benefits autoimmune patients are not completely understood.

In this study, we analyzed the peripheral blood derived from patients with MG before or after IVIg treatment in an attempt to identify defects in Treg that are involved in the pathogenesis of MG. We also analyzed other major lineages of $\mathrm{CD}^{+} \mathrm{T}$ cells including Th1, Th2, Th17, and Tfh given their pathologic significance in EMAG and MG [11]. The results indicated that Treg-associated CTLA-4 are underrepresented in MG patients and reduced expression and functional abnormalities in Treg-associated CTLA- 4 are related to the disease severity of MG. We also showed that IVIg exerted its therapeutic effects by restoring Treg fre- quency and function through its effects on dendritic cells (DCs). Further, we uncovered that the abnormalities of CTLA-4 were associated with the methylation binding site within the CTLA-4 promoter, which could aid in the design of novel therapeutic strategies towards epigenetic regulation of CTLA-4.

\section{Materials and Methods}

2.1. Patients. This study enrolled 39 patients with myasthenia gravis (MG) and 59 age-matched healthy donors (HD) from March 2011 to May 2015. None of the patients had received any immunosuppressive therapy before enrollment. All patients signed an informed consent prior to their inclusion in the study. The study has been approved by the ethics committee of Anhui Medical University and conforms to the Declaration of Helsinki and its later amendments. The MG patients were diagnosed by neurologists according to the standard clinical criteria and divided into five subgroups according to the MGFA clinical classification [38]. The clinical characteristics of MG patients are summarized in Table 1 and the patient's numbers were 9 for class I, 16 for class II, 9 for class III, and 5 for class IV. There were no patients in class V. All MG patients' peripheral blood samples were subjected to autoantibodies test including AChR and MuSK antibodies. Three patients are with ocular muscle weakness. The other 36 patients were anti-AChR antibody positive, and one of them was also anti-MuSK antibody positive. The mean \pm standard deviation $(\mathrm{SD})$ of the ages was $39.34 \pm 14.37$ years in the MG patients and $39.00 \pm 12.58$ years in the healthy donors. The sex ratio (male:female) was $1: 2$ in the MG patients and 19:40 in the heathy donors. 20 of the 39 MG patients were suffering from progressive general weakness and received two cycles of intermittent intravenous immunoglobulin (IVIg) treatment with a dose frequency of $0.4 \mathrm{mg} / \mathrm{kg} /$ day for five consecutive days. 13 of them underwent thymectomy after IVIg therapy. A quantitative MG scoring system (QMG score) was applied to objectively assess the disease severity [38].

2.2. Isolation of Lymphocytes from Periphery Blood. Periphery blood mononuclear cells (PBMCs) were isolated using a lysethen-wash step as described previously [25]. Basically, a total of $20 \mathrm{ml}$ venous blood was collected directly into a heparinized tube and diluted with sterile $\mathrm{pH} 7.2$ phosphate-buffered saline (PBS) at room temperature. The PBMCs were then isolated by density gradient centrifugation using Ficoll-Paque 
Plus (MP Biomedicals, Santa Ana, CA, USA). The acquired PBMCs were washed twice with $\mathrm{PBS}$ and resuspended at $1 \times 10^{7}$ cells $/ \mathrm{ml}$ for culture.

2.3. Flow Cytometry Assay. The flow cytometry assays were performed as described previously [39]. All the fluorescence-conjugated antibodies were purchased from BD Biosciences (Ashland, OR, USA). Briefly, PBMCs from healthy donors and patients were stained with the antibodies as indicated, followed by flow cytometry analysis with a BD Biosciences Digital LSR II (BD Biosciences, Franklin Lakes, NJ, USA). Data were analyzed using FlowJo software (Tree Star Inc., Ashland, OR, USA).

2.4. Enzyme-Linked Immunosorbent Assay (ELISA). IFN- $\gamma$, TNF- $\alpha$, IL-2, IL-4, IL-6, IL-10, IL-17A, and TGF- $\beta$ were detected by using human ELISA kits from BD Bioscience (Franklin Lakes, NJ, USA) according to the manufacturer's instructions. The concentrations of serum IL-21 in MG patients and healthy donors were determined by ELISA using the human IL-21 ELISA kit (R\&D Systems, Minneapolis, MN, USA) according to the manufacturer's instructions. Briefly, individual serum at 1:4 dilutions were subjected to ELISA analysis, and the concentrations of serum cytokines in individual samples were quantified by reference to standard curves. Determinations were performed in duplicate and results were expressed as $\mathrm{pg} / \mathrm{ml}$.

2.5. Purification and Sorting of Human Treg Cells. Human Treg cells and Teff cells were purified from the whole blood of healthy human donors. Firstly, $\mathrm{CD} 4^{+} \mathrm{T}$ cells were enriched using RosetteSep Human $\mathrm{CD}^{+}{ }^{+} \mathrm{T}$ Cell Enrichment Cocktail (STEMCELL Technologies, Vancouver, Canada). $\mathrm{CD}^{+}$cells were stained with anti-CD4, anti-CD25, and anti-CD127. Treg cells were gated on the $\mathrm{CD} 4^{+} \mathrm{CD} 25^{+} \mathrm{CD} 127^{-}$population, and Teff cells were gated on the $\mathrm{CD} 4^{+} \mathrm{CD} 25^{-} \mathrm{CD} 127^{+}$population. All the fluorescence-conjugated antibodies were purchased from BD Biosciences (Ashland, OR, USA).

2.6. Generation of Human DCs. CD $14^{+}$monocytes were isolated from PBMC by using CD14 magnetic beads (Miltenyi Biotec, Gladbach, Germany) and the purity was $>98 \%$. Monocytes were cultured in RPMI-1640 medium containing $10 \%$ fetal calf serum for 6 days in the presence of cytokines GM-CSF ( $1000 \mathrm{IU} / 10^{6}$ cells) and IL-4 (500 IU/ $10^{6}$ cells) to obtain DCs and were used for subsequent experiments.

2.7. Coculture of DCs with CD $4^{+}$T Cells. PBMC-derived DCs were extensively washed and were cocultured with $1 \times 10^{5}$ $\mathrm{CD}^{+} \mathrm{T}$ with a $1: 10$ ratio in 96-well $\mathrm{U}$-bottom plates as reported previously. Cocultures were maintained for 4 days and CTLA $-4^{+}$Tregs were analyzed by flow cytometry (LSR II; BD Biosciences) by using a combination of CD4, CD25, FOXP3, and CTLA-4 antibodies.

2.8. Bisulfite Sequencing. Bisulfite sequencing was performed as described previously [40]. Genomic DNA was prepared using an AllPrep DNA Mini Kit (Qiagen, Hilden, Germany). DNA methylation was detected in T cell subsets at the promoter region of CTLA-4. DNA was bisulfite treated using an EpiTect Plus Bisulfite Conversion Kit (Qiagen, Hilden, Germany) according to the manufacturer's instructions. PCR products were purified and sequenced. DNA methylation analysis was carried out using quantification tool for methylation analysis, and methylation was determined at each CpG dinucleotide [41].

2.9. Real-Time PCR. Real-time PCR analysis was performed as described previously [42]. Briefly, total RNA was isolated from cells with an RNeasy Mini Kit (Qiagen, Hilden, Germany) according to the manufacturer's instructions. Total RNA from each sample was reverse transcribed with oligo(dT) 20 using SuperScript III Reverse Transcriptase (Invitrogen, Camarillo, CA, USA) followed by real-time PCR. Primers for CTLA-4 were described as previously [43]. Real-time PCR was performed with SYBR Green PCR Master Mix reagents using an ABI Prism 7700 Sequence Detection System (Applied Biosystems, Foster City, CA, USA).

2.10. Statistical Analysis. Data analysis was performed by using SPSS version 16.0. The data with normal distribution are presented as the mean \pm standard deviation (SD). To reduce the error of test results at different time points, the patients and healthy donors at the same time point were compared using paired samples $T$ test. For the comparison between different treatment groups, the data were analyzed by one-way ANOVA and comparison between the two groups was carried out with a Bonferroni/Dunnett multiple comparison test. A $P$ value of less than 0.05 was considered statistically significant.

\section{Results}

3.1. Profile Comparison of $\mathrm{CD}^{+} T$ Subset Cells in $M G$ Patients and Healthy Donors. We conducted a comprehensive flow cytometry study to determine the frequency of $\mathrm{CD}^{+} \mathrm{T}$ cell subsets including Th1, Th2, Th17, Tfh, Treg, and CTLA $-4^{+}$Treg in the PBMCs of 59 healthy donors and 40 untreated MG patients. We used the following markers to identify each $\mathrm{CD}^{+} \mathrm{T}$ cell subset: Th1 $\left(\mathrm{CD} 4^{+} \mathrm{IFN}-\gamma^{+}\right)$ (Figure 1(a)), Th2 (CD4 $\left.{ }^{+} \mathrm{IL}_{-} 4^{+}\right)$(Figure 1(b)), Th17 $\left(\mathrm{CD} 4^{+-}\right.$ IL- $\left.17 \mathrm{~A}^{+}\right)$(Figure 1(c)), Tfh $\left(\mathrm{CD} 4^{+} \mathrm{CXCR} 5^{+} \mathrm{PD}-1^{\text {high }}\right)$ (Figure 1(d)), Treg $\left(\mathrm{CD} 4^{+} \mathrm{CD} 25^{+} \mathrm{FOXP}^{+}\right.$) (Figure 1(e)), and CTLA $-4^{+}$Treg $\left(\mathrm{CD} 4^{+} \mathrm{CD}_{2} 5^{+} \quad \mathrm{FOXP}^{+} \mathrm{CTLA}-4^{+}\right)$ (Figure 1(f)). The results are summarized in Figure $1(\mathrm{~g})$ and indicated that the mean frequency of Treg cells and CTLA $-4^{+}$Treg in MG patients $(2.35 \pm 0.42 \%$ and $0.91 \pm$ $0.31 \%$, respectively) was significantly lower than that in healthy donors $(4.70 \pm 0.76 \%$ and $1.90 \pm 0.63 \%$, respectively). In contrast, no significant difference was observed in the frequency of other $\mathrm{T}$ cell subsets including $\mathrm{Th} 1$ $(9.7 \pm 2.1 \%$ in $\mathrm{MG}$ vs. $9.1 \pm 1.8 \%$ in HD), Th2 $(0.62 \pm 0.28 \%$ in $\mathrm{MG}$ vs. $0.45 \pm 0.17 \%$ in $\mathrm{HD})$, Th17 $(1.23 \pm 0.31 \%$ in $\mathrm{MG}$ vs. $1.30 \pm 0.44 \%$ in $\mathrm{HD})$, and $\mathrm{Tfh}$ $(2.14 \pm 0.47 \%$ in $\mathrm{MG}$ vs. $2.80 \pm 0.64 \%)$.

3.2. The Profile of Secreted Cytokines in MG Patients. We applied ELISA assay to measure the serum concentrations of a range of cytokines in the MG patients without therapy 



(a)

(b)

Th17
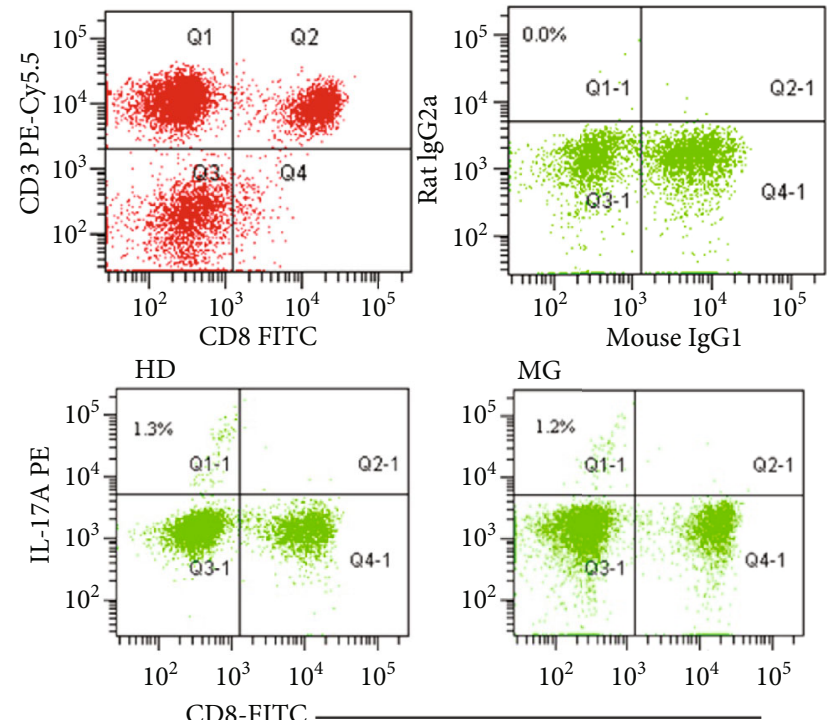

(c)

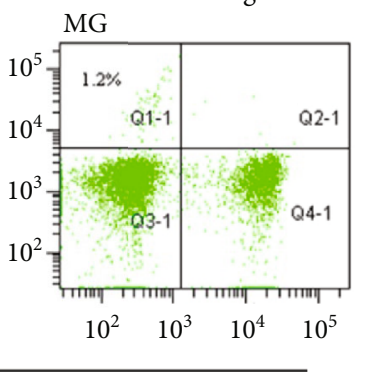

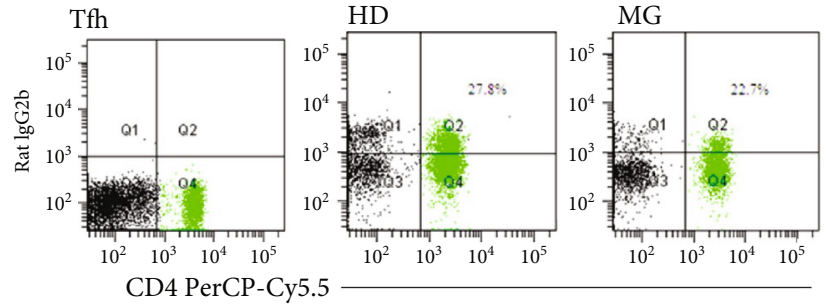

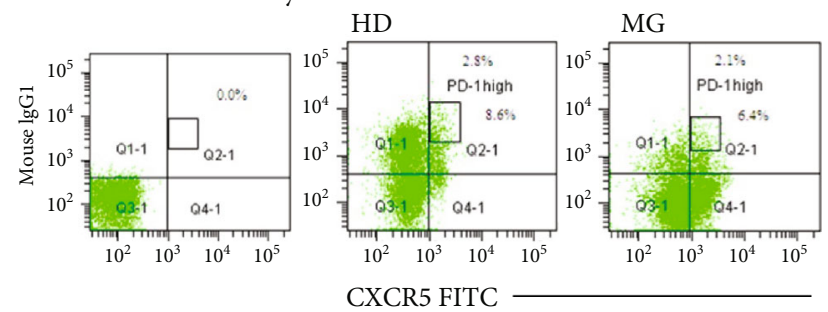

(d)

Figure 1: Continued. 

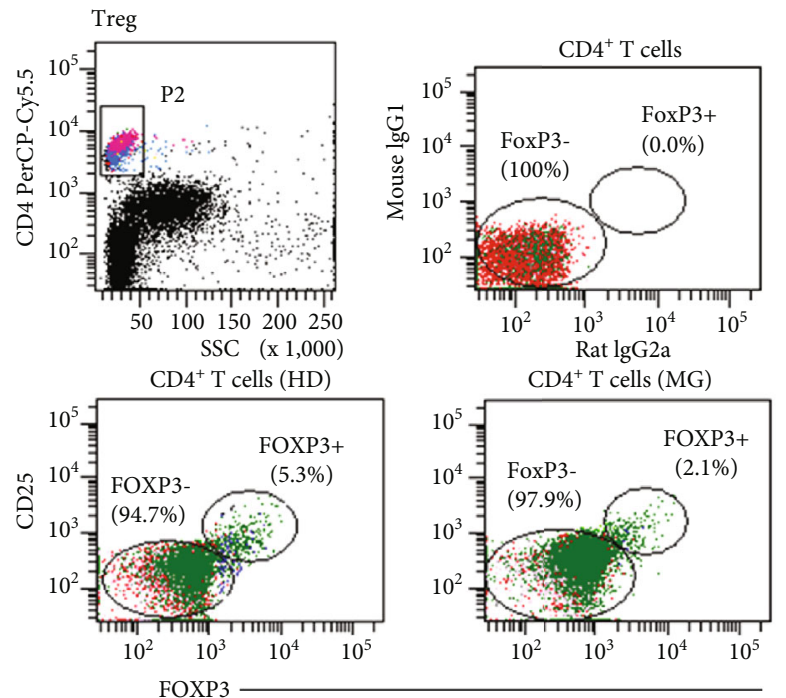

(e)
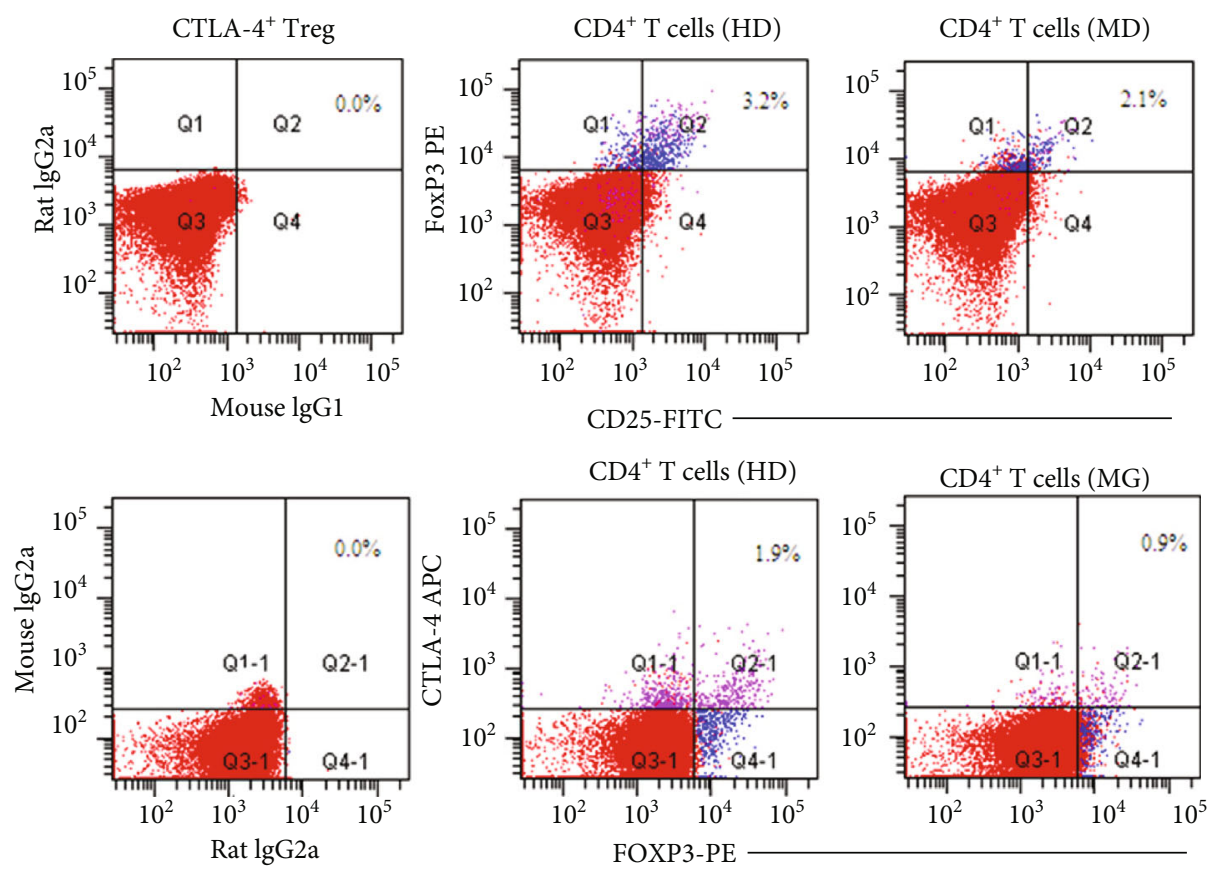

(f)

Figure 1: Continued. 


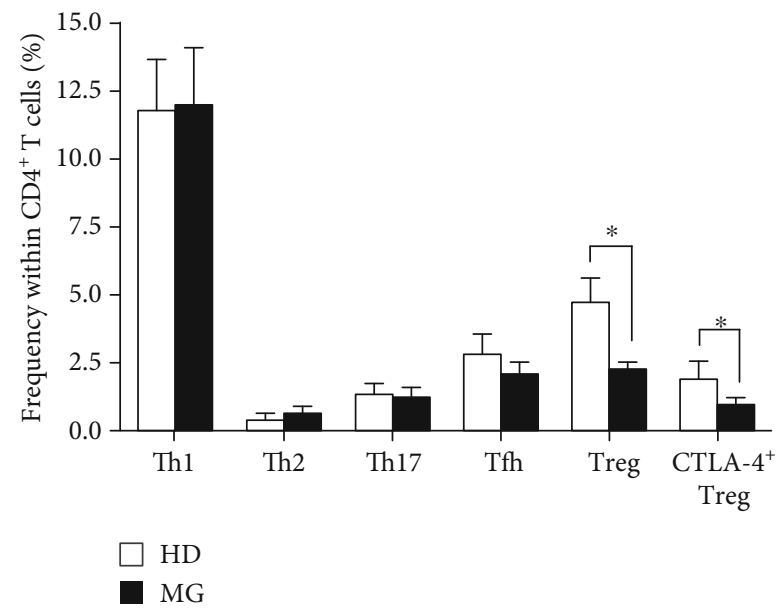

(g)

Figure 1: Phenotypic profiles of $\mathrm{CD} 4^{+} \mathrm{T}$ cell subsets reveal underrepresentation of Treg and CTLA- $4^{+}$Treg in MG patients. Representative FACS analysis of PBMCs from healthy donors and untreated MG patients was shown based on cell surface markers and/or intracellular cytokines for $\mathrm{CD} 4^{+} \mathrm{IFN}-\gamma^{+}$Th1 cells (a), CD $4^{+} \mathrm{IL}-4^{+}$Th2 cells (b), CD $4^{+} \mathrm{IL}-17 \mathrm{~A}^{+}$Th17 cells (c), CD $4^{+} \mathrm{CXCR} 5^{+} \mathrm{PD}-1^{\text {high }}$ Tfh cells (d), $\mathrm{CD} 4^{+} \mathrm{CD} 25^{+} \mathrm{FOXP}^{+}$Treg cells (e) and $\mathrm{CD} 4^{+} \mathrm{CD} 25^{+} \mathrm{FOXP}^{+} \mathrm{CTLA}-4^{+}$Treg cells (f). G. Comparison of the mean frequency of $\mathrm{CD} 4^{+} \mathrm{T}$ cell subsets based on FACS analysis using the aforementioned markers in healthy donors $(n=59)$ and untreated MG patients $(n=39)$. Data are expressed as mean \pm SD. ${ }^{*} P<0.05$.

and healthy donors: IFN- $\gamma$, TNF- $\alpha$, IL-4, IL-17A, IL-10, TGF- $\beta$, IL-21, IL-2, and IL-6. The results in Figure 2 indicated the level of IFN- $\gamma$, TNF- $\alpha$, and IL- 4 was higher in MG patient, but statistics revealed no significant difference from healthy donors. The level of IL-17A, IL-21, TGF- $\beta$, and IL-10 in MG patients was insignificantly lower than healthy donors, respectively. The level of IL-2 and IL-6 remained relatively unchanged in $\mathrm{MG}$ patients. We also quantified the mRNA level of each cytokine by qRT-PCR and the results were compatible with the ELISA assay (data not shown). The majority of cytokine levels measured in our study are consistent with previously published reports that showed no significant change of cytokines secreted by PBMC were detected between MG patients and healthy donors [44].

3.3. Dynamic Profiling of Treg Cells in MG Patients in Response to IVIg Therapy. Intravenous immunoglobulin (IVIg) is widely used in the treatment of MG patients. In this study, 20 out of $39 \mathrm{MG}$ patients received two courses of intravenous immunoglobulin (IVIg) therapy with each course consisting of a dose of $0.4 \mathrm{mg} / \mathrm{kg} / \mathrm{day}$ for five consecutive days. The therapeutic effects of IVIg, evaluated by dynamic profiling of individual and mean QMG score during IVIg therapy (Figures 3(a) and 3(b)), indicated 16 out of 20 $(80 \%)$ were relieved after one course of IVIg treatment and 19 out of 20 were significantly improved after two courses of IVIg treatment. The frequency of circulating Treg $\left(\mathrm{CD} 4^{+}\right.$ $\mathrm{CD}_{25}{ }^{+} \mathrm{FOXP}^{+}$) (Figures $3(\mathrm{c})$ and $3(\mathrm{~d})$ ) and CTLA $-4^{+}$Treg $\left(\mathrm{CD} 4^{+} \mathrm{CD} 25^{+} \mathrm{FOXP}^{+} \mathrm{CTLA}^{+} 4^{+}\right.$) (Figures $3(\mathrm{e})$ and $\left.3(\mathrm{f})\right)$ was significantly increased by IVIg. The dynamic change of the frequency of Treg/CTLA $-4^{+}$Treg cells and clinical symptom by IVIg therapy, and the inverse relationship between them, suggested a correlation between immunologic disorder in
MG patients and peripheral Tregs and CTLA $-4^{+}$Treg population.

3.4. IVIg Therapy Induces Treg and CTLA-4 $4^{+}$Treg Cells through DCs in MG. The beneficiary effects of IVIg on MG patients and the inverse relationship between circulating Tregs/CTLA $-4^{+}$Tregs and disease severity of MG patients prompted us to investigate the mechanisms of expansion of Tregs/CTLA $-4^{+}$Tregs by IVIg. Because induction of Tregs $\left(\mathrm{CD} 4^{+} \mathrm{CD} 25^{+} \mathrm{FOXP}^{+}\right)$in the periphery of healthy donors has been shown to involve the presence of antigenpresenting cells such as dendritic cells (DCs) [45], we sought to determine whether IVIg-induced expansion of circulating Tregs in MG patients through DCs as well. We treated sixday-old monocyte-derived DCs from MG patients with IVIg at a dose that is compatible with that used in the IVIg therapy $(2 \mathrm{mg} / \mathrm{ml}$ or $4 \mathrm{mg} / \mathrm{ml})$. The DCs were then extensively washed and cocultured with $\mathrm{CD}^{+} \mathrm{T}$ cells from PBMC of MG patients for 4 days. We assessed the expression of Tregs $\left(\mathrm{CD} 4^{+} \mathrm{CD} 25^{+} \mathrm{FOXP}^{+}\right)$and CTLA $-4^{+}$Tregs $\left(\mathrm{CD} 4^{+} \mathrm{CD} 25^{+-}\right.$ FOXP $3^{+}$CTLA $-4^{+}$) before or after IVIg treatment by flow cytometry. Compared with untreated DCs or HSA-treated DCs, IVIg-treated DCs significantly increased the expression of Tregs and CTLA $-4^{+}$Tregs and in a dose-dependent manner (Figures 4(a)-4(d)). In contrast, incubation of $\mathrm{CD} 4^{+} \mathrm{T}$ cells with IVIg prior to coculture with DCs did not increase the expression of Tregs or CTLA $-4^{+}$Tregs (Figures 4(c) and $4(d)$ ), suggesting that IVIg-induced expansion of Tregs and CTLA $-4^{+}$Tregs in MG patients through modulation on DCs and the ability of DCs to induce Tregs and CTLA- $4^{+}$ Tregs is not altered in MG patients.

3.5. Defective CTLA-4 in MG Treg Is Associated with Diminished Transcription Activity of CTLA-4 Gene Promoter following Methylation. Having established the role 


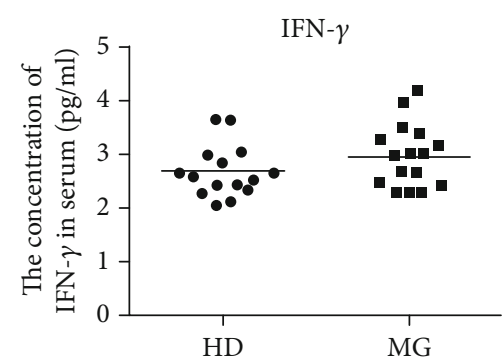

(a)

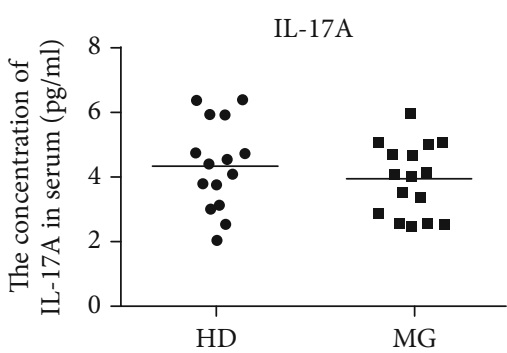

(d)

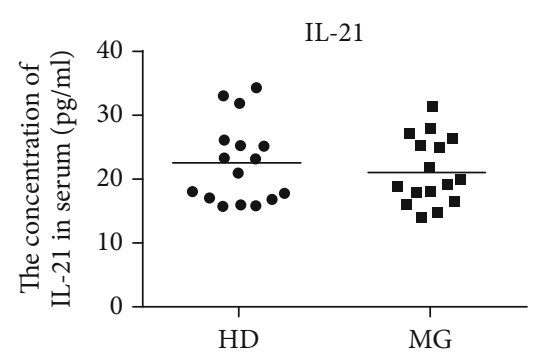

(g)

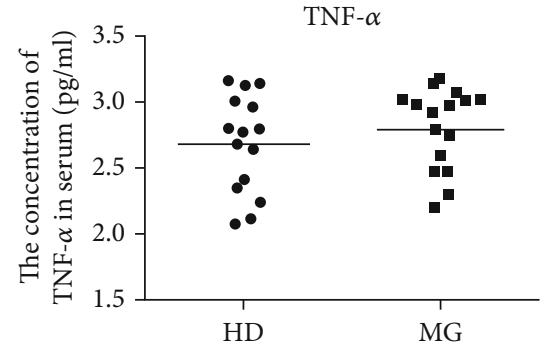

(b)

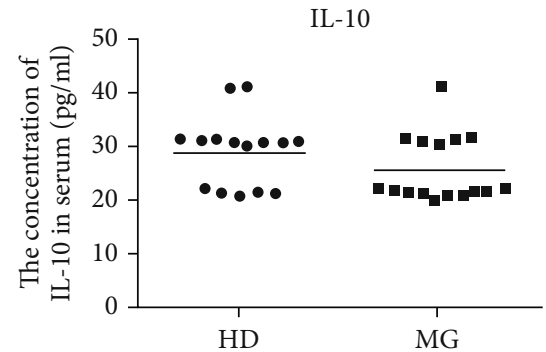

(e)

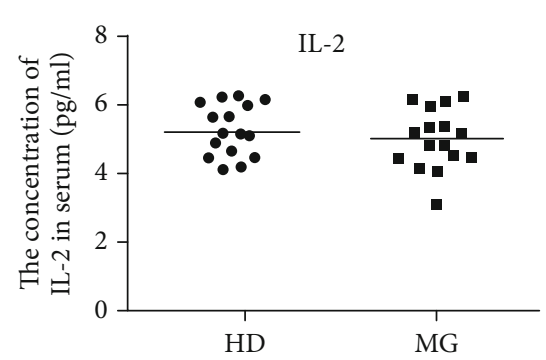

(h)

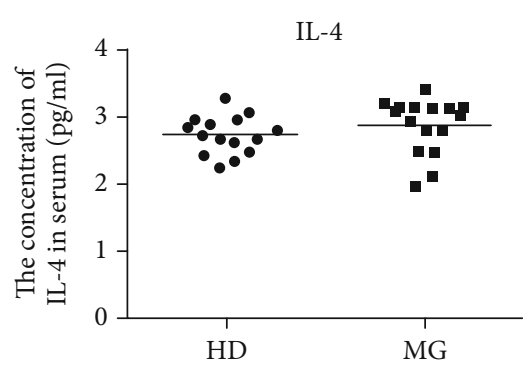

(c)

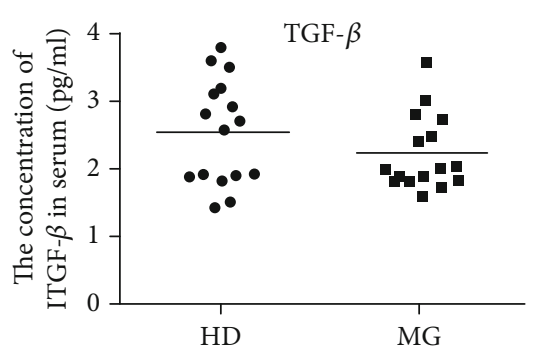

(f)

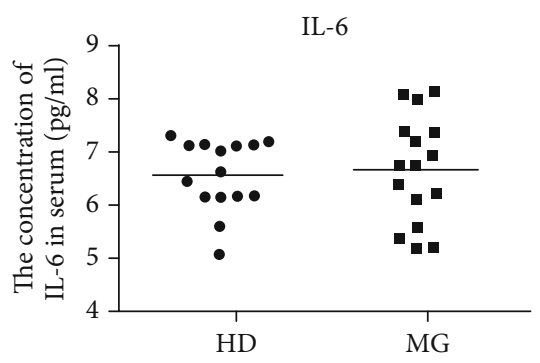

(i)

FIGURE 2: Cytokine profiles of $\mathrm{CD}^{+} \mathrm{T}$ cell subset are unchanged in MG patients. The level of cytokines secreted by PBMC from MG patients $(n=16)$ and healthy donors $(n=16)$ was measured by ELISA including Th1-associated IFN- $\gamma$ (a) and TNF- $\alpha$ (b), Th2-secreted IL-4 (c), Th17-specific IL-17A (d), Treg-associated IL-10 (e) and TGF- $\beta$ (f), Tfh-secreted IL-21 (g), and another two T cell-secreted cytokines IL-2 (h) and IL-6(i). Each data point represents an individual subject. The horizontal lines represent the average level.

of CTLA-4 in MG pathology and therapy, we sought to investigate the mechanism underlying the defects in CTLA4 in MG patients. We first determined whether the reduction in CTLA-4 expression occurs at a transcriptional level by comparing the mRNA level of CTLA-4 in the Tregs in MG patients and healthy donors. The results indicated that the expression level of transcripts encoding the total CTLA-4 was significantly reduced in MG patients and IVIg therapy restored the expression of CTLA-4 (Figure 5(a)).

Because DNA methylation followed by transcriptional silencing has been recognized as an epigenetic mechanism in maintaining $\mathrm{T}$ cell function and altered DNA methylation patterns have been implicated in autoimmunity $[40,46]$, we hypothesized that altered methylation within CTLA-4 gene promoter can attenuate CTLA-4 gene expression in MG Tregs. We compared the methylation state of CpGs within CTLA-4 gene promoter region in Tregs of MG patients and healthy donors and observed increased methylation at -658 and -793 CpGs (position relative to the ATG start codon) in MG Tregs (Figure 5(b)). Interestingly, IVIg therapy significantly reduced the methylation level at these two sites in MG patients (Figure 5(c)). Taken together, these results indicated that CTLA-4 exhibited lower expression level due to promoter methylations in MG patients; however, IVIg therapy restored CTLA-4 expression through reducing methylation level.

\section{Discussion}

Myasthenia gravis (MG) is a $\mathrm{CD} 4^{+} \mathrm{T}$ cell-dependent autoimmune disease and intravenous immunoglobulin (IVIg) has been the mainstay of immunotherapeutic therapy. The subsets of $\mathrm{CD} 4^{+} \mathrm{T}$ cells involved in this disease and IVIg therapy, however, remain to be investigated $[12,36]$. Through this study, we have established the roles of CTLA $-4^{+}$Treg cells in MG and their dynamic profiling in MG patients with IVIg therapy. Initially, we demonstrated that CTLA $-4^{+}$Treg cells exhibited a lower level than those of healthy donors and IVIg therapy expands CTLA- $4^{+}$Treg cells in MG patients. Mechanistically, we found that IVIg-induced CTLA $-4^{+}$Treg cell expansion depends on the modulation of dendritic cells. Finally, hypermethylation of the CTLA-4 promoter was 


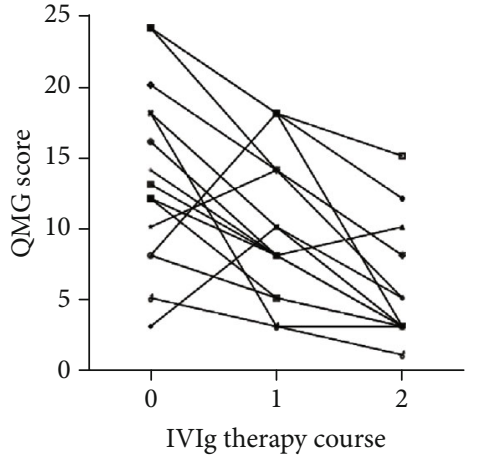

(a)

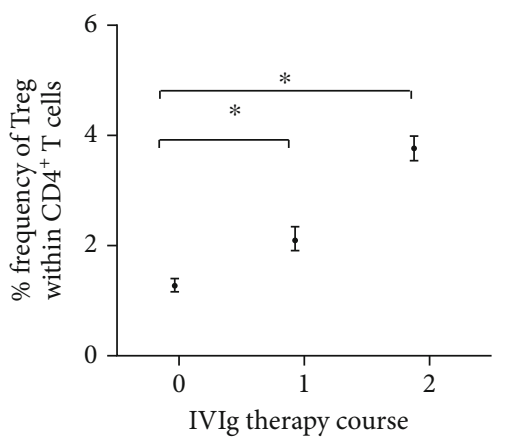

(d)

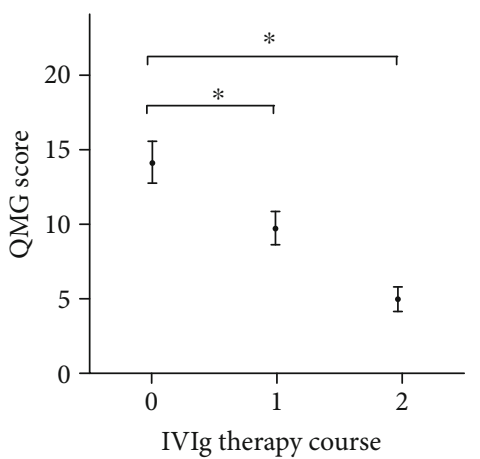

(b)

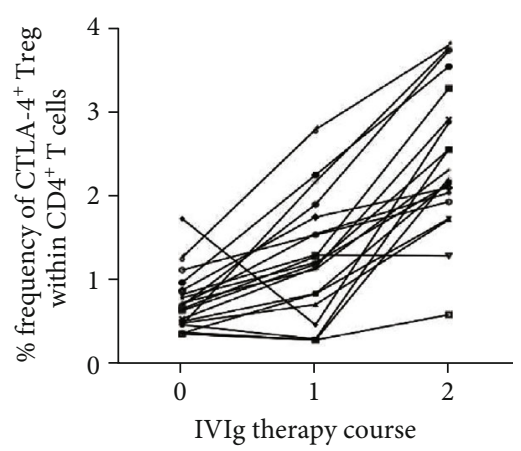

(e)

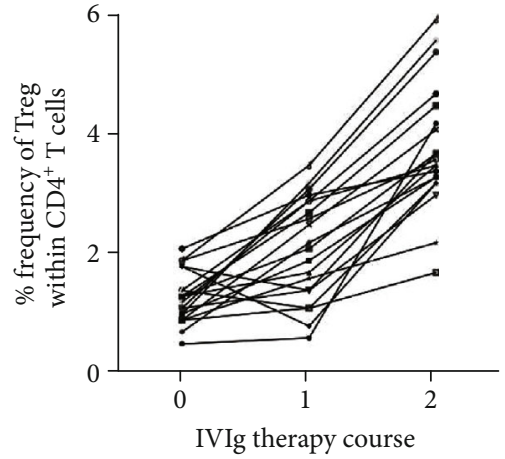

(c)

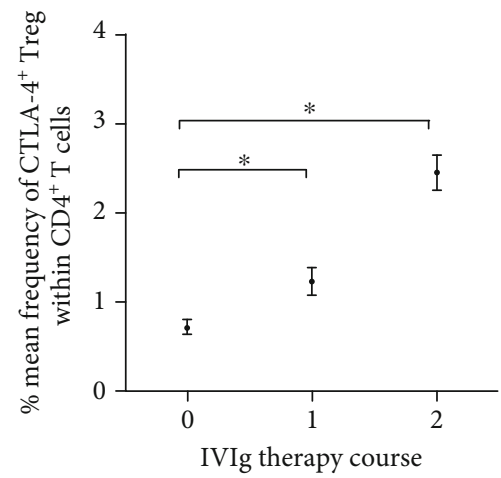

(f)

FIGURE 3: Dynamic changes of regulatory $\mathrm{CD} 4^{+} \mathrm{T}$ cells in MG patients and their QMG scores during IVIg therapy demonstrated a positive correlation between IVIg therapeutic effect and frequency of Tregs and CTLA-4 ${ }^{+}$Tregs. The individual (a) and mean (b) QMG scores were determined for MG patients $(n=20)$ during the two courses of IVIg therapy. The individual and mean frequency of $\mathrm{CD} 4^{+} \mathrm{CD} 25^{+} \mathrm{FOXP} 3^{+}$ Treg cells $(\mathrm{c}, \mathrm{d})$ and $\mathrm{CD} 4^{+} \mathrm{CD} 25^{+} \mathrm{FOXP} 3^{+} \mathrm{CTLA}-4^{+}$Treg cells $(\mathrm{e}, \mathrm{f})$ were measured by FACS analysis of PBMCs from IVIg-treated MG patients $(n=20)$.

observed in MG patients and IVIg reversed this effect. Taken together, these findings suggest that the key role of CTLA-4 in functionally defected Treg cells and may provide a potential approach for the therapy of this disease.

Cytotoxic T lymphocyte antigen- (CTLA-) 4 is an inhibitory relative of the $\mathrm{T}$ cell costimulatory molecule $\mathrm{CD} 28$. While $\mathrm{CD} 28$ signaling promotes $\mathrm{T}$ cell activation, CTLA-4 serves an immune regulatory function, suppressing the $\mathrm{T}$ cell response. Widespread recognition of the importance of the CTLA-4 pathway came about when mice deficient of the CTLA-4 gene were found to exhibit dysregulated $\mathrm{T}$ cell immunity resulting in tissue infiltration and death around $3 \mathrm{wk}$ of age [21,32,47]. Increasing reports of allelic association between specific polymorphisms of CTLA-4 gene with various autoimmune diseases support the idea that the CTLA-4 region is an important locus for autoimmune disease in general. Several studies have suggested the association between mRNA level and specific polymorphisms of CTLA-4 with MG. The role of CTLA-4 and its related T cells in MG, however, remain to be investigated. $[35,48-50]$. Here, we measured the frequencies of $\mathrm{CD}^{+} \mathrm{T}$ cell subsets in MG patients and found that the mean frequency of Treg cells and CTLA $-4^{+}$Treg in MG patients was significantly lower than that in healthy donors. As for other $\mathrm{CD} 4^{+} \mathrm{T}$ cell subsets, there is no sig- nificant difference between in healthy donors and $\mathrm{MG}$ patients. This result indicates that CTLA-4 is involved in the pathogenesis of MG.

Intravenous immunoglobulin (IVIg) is extensively used in the treatment of autoimmune and inflammatory diseases. Although IVIg therapy has been used for close to 3 decades, the mechanism of action is incompletely understood [36, 37]. Treg cells play a critical role in the maintenance of immune tolerance and prevention of autoimmunity. Deficiency of Tregs or their defective functions lead to autoimmune diseases, whereas Treg expansion and function regains are associated with recovery from autoimmune diseases. IVIg expands $\mathrm{FOXP}^{+}{ }^{+}$Treg cells mediated by dendritic cells (DCs) in autoimmune diseases [51, 52]. CTLA-4 plays a critical role in the function of Tregs and it incorporates with FOXP3 to represent the complete suppression function of Tregs. As for MG, a recent study suggests that immunosuppressive treatment leads to Treg subpopulation change in MG patients. This study has well established the association of immunosuppressive treatments with Treg subpopulation recovery [26]. As we know, there is no data suggesting the association between CTLA-4 and IVIg therapy in autoimmune diseases $[53,54]$. Here, we found that IVIg therapy expanded CTLA- $4^{+}$Tregs in MG patients. We firstly established the possible association between CTLA $-4^{+}$Treg 

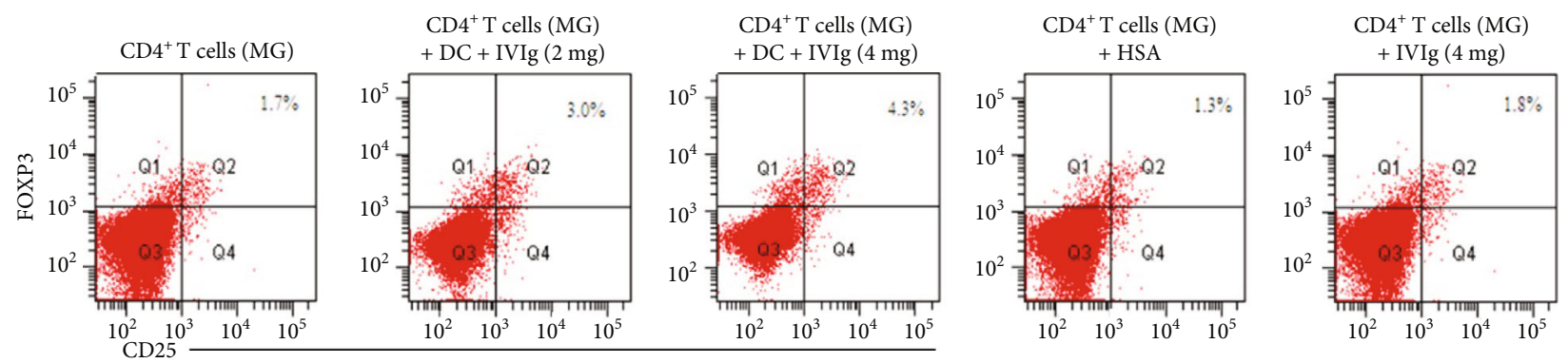

(a)
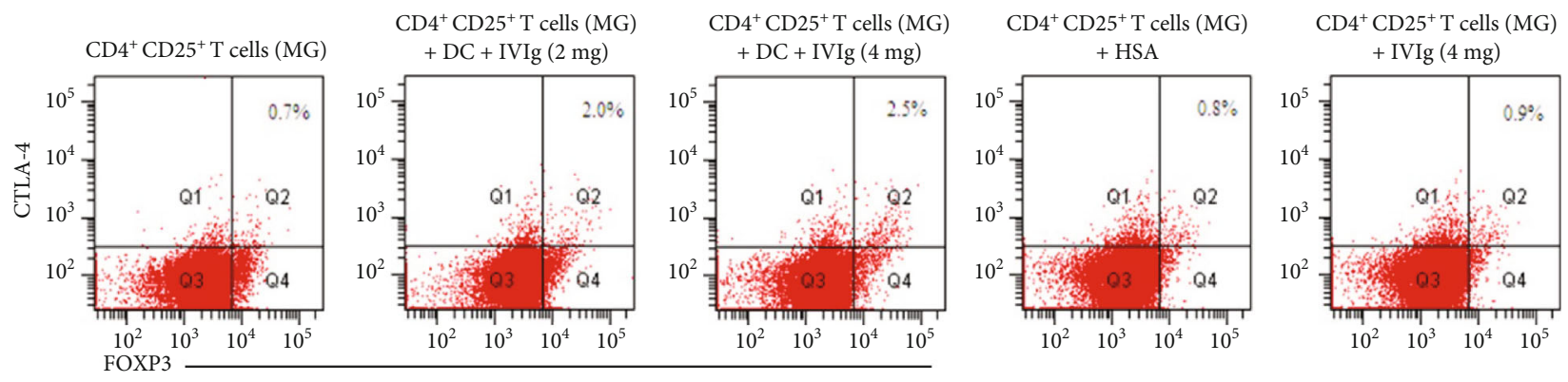

(b)

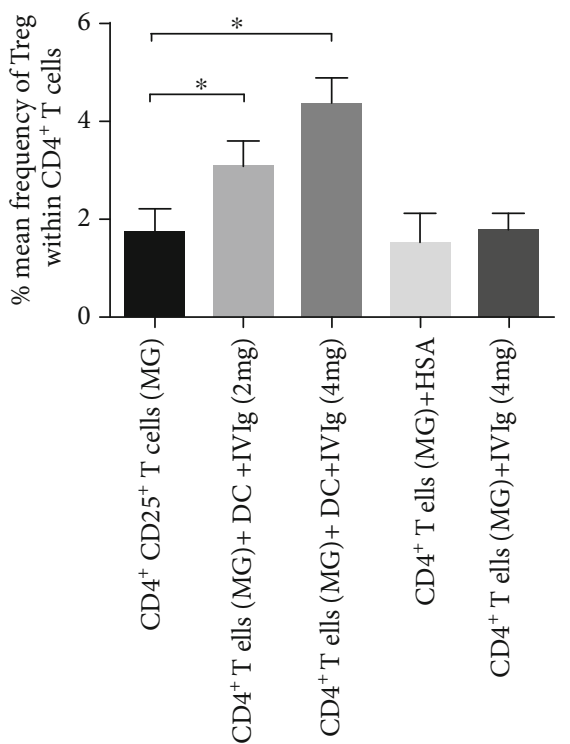

(c)

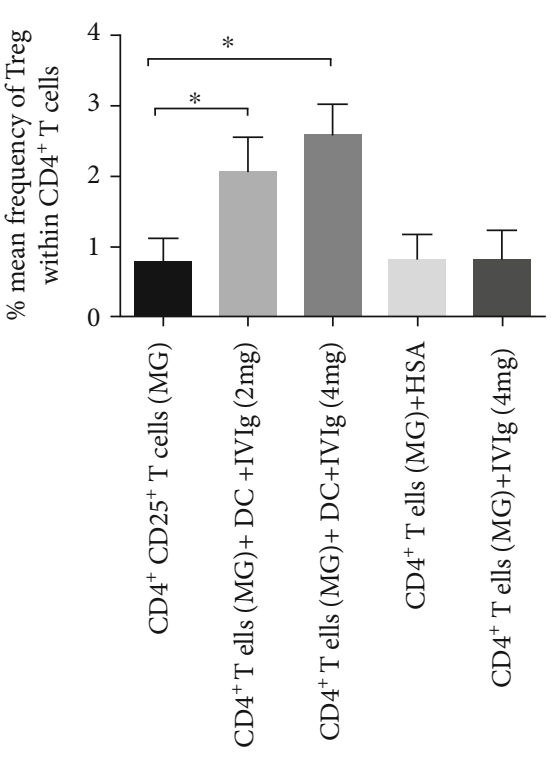

(d)

FIgURE 4: IVIg therapy induces Treg and CTLA- $4^{+}$Treg cells through DCs in MG. Monocyte-derived DCs from MG patients were treated with vehicle, $2 \mathrm{mg} / \mathrm{ml}$ or $4 \mathrm{mg} / \mathrm{ml}$ IVIg and then cocultured with $\mathrm{CD}^{4+} \mathrm{T}$ cells from PBMC of MG patients for 4 days. Treg cells $\left(\mathrm{CD} 4^{+} \mathrm{CD} 25^{+} \mathrm{FOXP}^{+}\right)$and CTLA $-4^{+}$Treg cells $\left(\mathrm{CD} 4^{+} \mathrm{CD} 25^{+} \mathrm{FOXP} 3^{+} \mathrm{CTLA}-4^{+}\right)$were then detected by flow cytometry $(\mathrm{a}$, b). At least three independent experiments were performed and statistical significance was determined by $T$ test $(c, d)$. Data are expressed as mean \pm SD. ${ }^{*} P<0.05$.

expansion and IVIG therapy. Since CTLA-4 plays a critical role in MG recovery, it would be a very important strategy to increase CTLA- 4 of Treg in the therapy of MG and other autoimmune diseases. Considering the limitation of patient sample size in this study, we will perform our further study using more $M G$ patient samples to confirm the preliminary data.

DNA methylation plays a critical role in gene expression regulation through establishing and maintaining the DNA methylation status in gene promoters. DNA methylation mainly occurs in the $\mathrm{CpG}$ islands of gene promoters and it decreases gene expression by inhibiting the recruitments of transcriptional factors. It has been shown that CTLA-4 promoter methylation involved the pathology of rheumatoid arthritis $[40,46]$. This led us to postulate that DNA methylation of CTLA-4 promoter also occurs in MG patients. As a result, hypermethylation at -658 and $-793 \mathrm{CpGs}$ of CTLA-4 promoter was observed in MG patients. Importantly, IVIg 


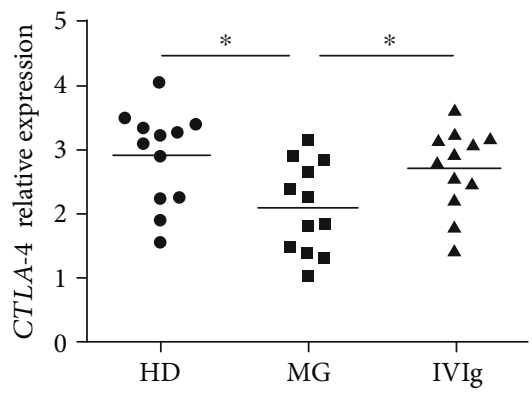

(a)

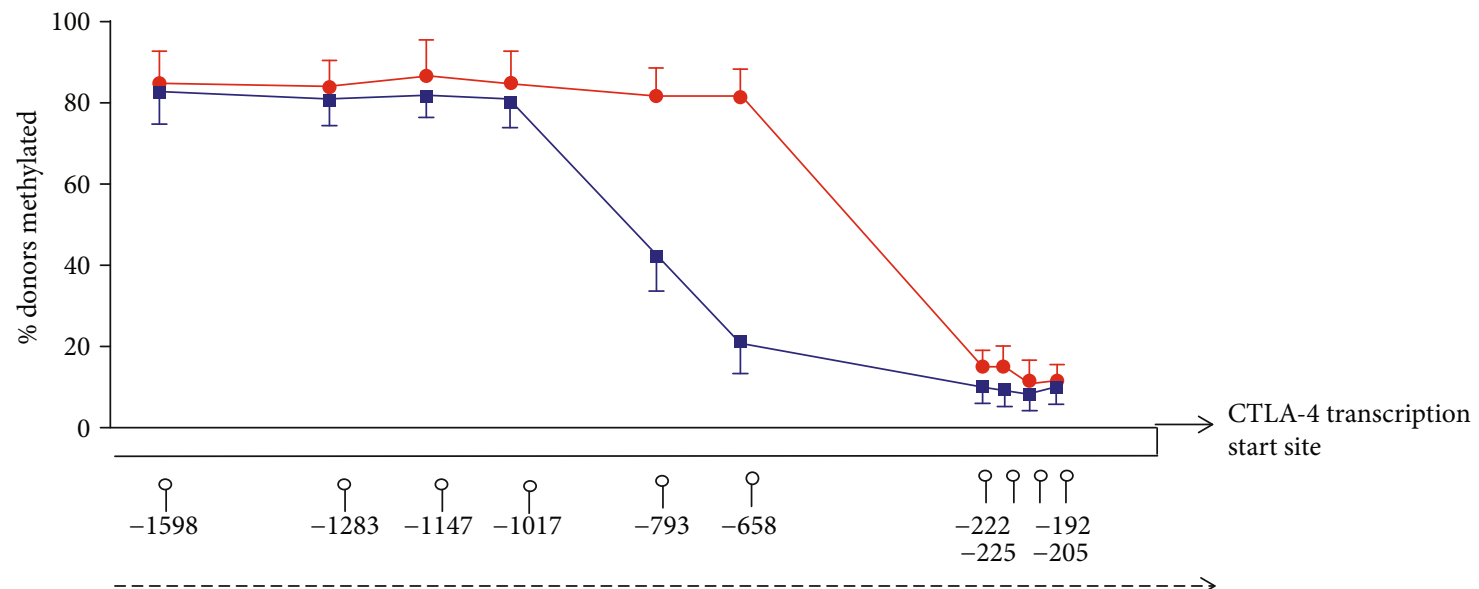

The promoter CTLA-4 gene on chromosome $2 \mathrm{q} 33.2$

$\rightarrow-\mathrm{HD}$

$\rightarrow \mathrm{MG}$

(b)

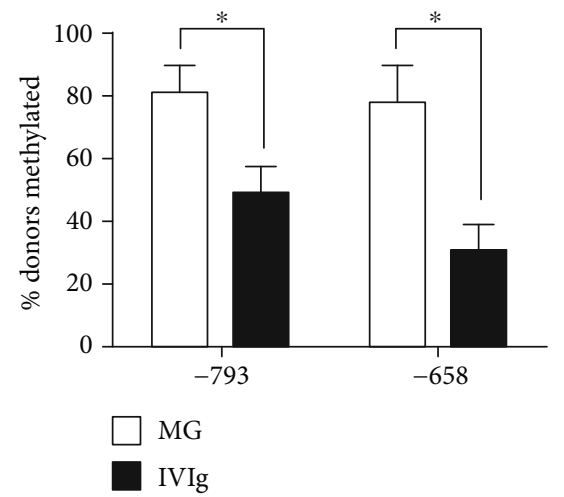

(c)

FIGURE 5: Quantitative analysis of CTLA-4 mRNA in Treg cells from myasthenia gravis patients (MG) and healthy donors (HD). (a) Total RNA was extracted from sorted Treg cells of MG and HD and then real-time PCR was performed to measure CTLA-4 mRNA level. (b) Genomic DNA was prepared from sorted Treg cells and methylation status within CTLA-4 promoter was detected. The methylation percentage within CTLA-4 promoter in Treg cells from HD and MG $(n=10)$ was shown. (c) The methylation percentage at -658 and -793 CpGs in Treg cells from MG and MG with IVIg therapy $(n=12)$ is shown. Data are expressed as mean \pm SD. ${ }^{*} P<0.05$.

therapy reversed the hypermethylation of CTLA-4 promoter. A recent study suggests that the hypermethylation of CTLA-4 promoter is associated with the pathogenesis of MG [55]. This and our studies indicated that it may be an alternative therapy strategy to inhibit hypermethylation of CTLA-4 promoter in MG patients. Another study also reported that IVIg treatment leads to methylation alterations of inflammatory immune-associated genes in Kawasaki disease. An interesting but challenging question raised by these results is what causes the methylation change to occur and how IVIg therapy reverses this effect in the CTLA-4 gene promoter. We attempted to address this 
mechanistically through RNA-seq in MG patients but we failed to identify a potential factor. We will try other molecular tools as well as performing RNA-seq using more samples.

\section{Conclusions}

In summary, our preliminary data suggest that CTLA-4 may play a role in the disease progress and recovery of MG.

\section{Data Availability}

The data used to support the findings of this study are available from the corresponding authors upon request.

\section{Conflicts of Interest}

The authors declared that they have no conflicts of interest to this work.

\section{Authors' Contributions}

Wenhua Xu and Mingshan Ren contributed equally to this work.

\section{Acknowledgments}

This work was supported by the National Natural Science Foundation of China (Grant Nos. 31660325 and 21004056) and University Science and Technology Landing Project of Jiangxi Province (Grant No. 93KJLD12093). We thank Alex Meredith for his editor assistance.

\section{References}

[1] D. B. Drachman, R. N. Adams, L. F. Josifek, and S. G. Self, "Functional activities of autoantibodies to acetylcholine receptors and the clinical severity of myasthenia gravis," The New England Journal of Medicine, vol. 307, no. 13, pp. 769775, 1982.

[2] M. Milani, N. Ostlie, W. Wang, and B. M. Conti-Fine, "T cells and cytokines in the pathogenesis of acquired myasthenia gravis," Annals of the New York Academy of Sciences, vol. 998, pp. 284-307, 2003.

[3] J. Luo and J. Lindstrom, "Acetylcholine receptor-specific immunosuppressive therapy of experimental autoimmune myasthenia gravis and myasthenia gravis," Annals of the New York Academy of Sciences, vol. 1413, no. 1, pp. 76-81, 2018.

[4] R. Hohlfeld, K. V. Toyka, K. Heininger, H. Grosse-Wilde, and I. Kalies, "Autoimmune human $\mathrm{T}$ lymphocytes specific for acetylcholine receptor," Nature, vol. 310, no. 5974, pp. 244246, 1984.

[5] N. Sommer, G. C. Harcourt, N. Willcox, D. Beeson, and J. Newsom-Davis, "Acetylcholine receptor-reactive T lymphocytes from healthy subjects and myasthenia gravis patients," Neurology, vol. 41, no. 8, pp. 1270-1276, 1991.

[6] L. L. Kusner, M. Sengupta, and H. J. Kaminski, "Acetylcholine receptor antibody-mediated animal models of myasthenia gravis and the role of complement," Annals of the New York Academy of Sciences., vol. 1413, no. 1, pp. 136-142, 2018.
[7] L. Zhou, M. M. Chong, and D. R. Littman, "Plasticity of CD4+ $\mathrm{T}$ cell lineage differentiation," Immunity, vol. 30, no. 5, pp. 646-655, 2009.

[8] J. A. Villegas, J. Van Wassenhove, R. Le Panse, S. BerrihAknin, and N. Dragin, "An imbalance between regulatory $\mathrm{T}$ cells and T helper 17 cells in acetylcholine receptor-positive myasthenia gravis patients," Annals of the New York Academy of Sciences, vol. 1413, no. 1, pp. 154-162, 2018.

[9] A. Kalinkovich, G. Gabdulina, and G. Livshits, "Autoimmunity, inflammation, and dysbiosis mutually govern the transition from the preclinical to the clinical stage of rheumatoid arthritis," Immunologic Research, vol. 66, no. 6, pp. 696-709, 2018.

[10] J. Zhu and W. E. Paul, "CD4 T cells: fates, functions, and faults," Blood, vol. 112, no. 5, pp. 1557-1569, 2008.

[11] S. Berrih-Aknin and R. Le Panse, "Myasthenia gravis: a comprehensive review of immune dysregulation and etiological mechanisms," Journal of Autoimmunity, vol. 52, pp. 90-100, 2014.

[12] K. M. Danikowski, S. Jayaraman, and B. S. Prabhakar, "Regulatory $\mathrm{T}$ cells in multiple sclerosis and myasthenia gravis," Journal of Neuroinflammation, vol. 14, no. 1, p. 117, 2017.

[13] V. Dardalhon, T. Korn, V. K. Kuchroo, and A. C. Anderson, "Role of Th1 and Th17 cells in organ-specific autoimmunity," Journal of Autoimmunity, vol. 31, pp. 252-256, 2008.

[14] G. X. Zhang, L. Y. Yu, F. D. Shi et al., "Linomide suppresses both Th1 and Th2 cytokines in experimental autoimmune myasthenia gravis," Journal of Neuroimmunology, vol. 73, no. 1-2, pp. 175-182, 1997.

[15] Q. F. Kong, B. Sun, S. S. Bai et al., “Administration of bone marrow stromal cells ameliorates experimental autoimmune myasthenia gravis by altering the balance of Th1/Th2/Th17/Treg cell subsets through the secretion of TGF-beta," Journal of Neuroimmunology, vol. 207, no. 1-2, pp. 83-91, 2009.

[16] M. Masuda, M. Matsumoto, S. Tanaka et al., "Clinical implication of peripheral CD4+CD25+ regulatory T cells and Th17 cells in myasthenia gravis patients," Journal of Neuroimmunology, vol. 225, no. 1-2, pp. 123-131, 2010.

[17] M. Zhang, Y. Zhou, J. Guo et al., "Thymic TFH cells involved in the pathogenesis of myasthenia gravis with thymoma," Experimental neurology, vol. 254, pp. 200-205, 2014.

[18] C. S. Ma, E. K. Deenick, M. Batten, and S. G. Tangye, "The origins, function, and regulation of T follicular helper cells," The Journal of Experimental Medicine, vol. 209, no. 7, pp. 12411253, 2012.

[19] J. H. Buckner, "Mechanisms of impaired regulation by $\mathrm{CD}^{+-}$ $\mathrm{CD}_{2} 5^{+} \mathrm{FOXP}^{+}$regulatory $\mathrm{T}$ cells in human autoimmune diseases," Nature Reviews Immunology, vol. 10, no. 12, pp. 849859,2010

[20] D. A. Vignali, L. W. Collison, and C. J. Workman, "How regulatory T cells work," Nature Reviews Immunology, vol. 8, no. 7, pp. 523-532, 2008.

[21] M. Alahgholi-Hajibehzad, P. Kasapoglu, R. Jafari, and N. Rezaei, "The role of T regulatory cells in immunopathogenesis of myasthenia gravis: implications for therapeutics," Expert Review of Clinical Immunology, vol. 11, no. 7, pp. 859-870, 2015.

[22] A. Balandina, S. Lecart, P. Dartevelle, A. Saoudi, and S. BerrihAknin, "Functional defect of regulatory $\mathrm{CD} 4^{+} \mathrm{CD} 25^{+} \mathrm{T}$ cells in 
the thymus of patients with autoimmune myasthenia gravis," Blood, vol. 105, no. 2, pp. 735-741, 2005.

[23] S. Gertel-Lapter, K. Mizrachi, S. Berrih-Aknin, S. Fuchs, and M. C. Souroujon, "Impairment of regulatory T cells in myasthenia gravis: studies in an experimental model," Autoimmunity Reviews, vol. 12, no. 9, pp. 894-903, 2013.

[24] A. Gradolatto, D. Nazzal, F. Truffault et al., "Both Treg cells and Tconv cells are defective in the myasthenia gravis thymus: roles of IL-17 and TNF- $\alpha$," Journal of Autoimmunity, vol. 52, pp. 53-63, 2014.

[25] W. H. Xu, A. M. Zhang, M. S. Ren et al., "Changes of Tregassociated molecules on CD4+CD25 + Treg cells in myasthenia gravis and effects of immunosuppressants," Journal of Clinical Immunology, vol. 32, no. 5, pp. 975-983, 2012.

[26] S. Kohler, T. O. P. Keil, S. Hoffmann et al., "CD4 ${ }^{+}$FoxP3 $^{+}$T regulatory cell subsets in myasthenia gravis patients," Clinical Immunology, vol. 179, pp. 40-46, 2017.

[27] S. E. Allan, S. Q. Crome, N. K. Crellin et al., "Activationinduced FOXP3 in human T effector cells does not suppress proliferation or cytokine production," International Immunology, vol. 19, no. 4, pp. 345-354, 2007.

[28] M. E. Morgan, J. H. van Bilsen, A. M. Bakker et al., "Expression of FOXP 3 mRNA is not confined to $\mathrm{CD} 4^{+} \mathrm{CD} 25^{+} \mathrm{T}$ regulatory cells in humans," Human Immunology, vol. 66, no. 1, pp. 1320, 2005.

[29] J. Wang, A. Ioan-Facsinay, E. I. van der Voort, T. W. Huizinga, and R. E. Toes, "Transient expression of FOXP3 in human activated nonregulatory $\mathrm{CD}^{+} \mathrm{T}$ cells," European Journal of Immunology, vol. 37, no. 1, pp. 129-138, 2007.

[30] M. A. Gavin, T. R. Torgerson, E. Houston et al., "Single-cell analysis of normal and FOXP3-mutant human T cells: FOXP3 expression without regulatory T cell development," Proceedings of the National Academy of Sciences of the United States of America, vol. 103, no. 17, pp. 6659-6664, 2006.

[31] T. Takahashi, T. Tagami, S. Yamazaki et al., "Immunologic self-tolerance maintained by $\mathrm{CD} 25^{+} \mathrm{CD} 4^{+}$regulatory $\mathrm{T}$ cells constitutively expressing cytotoxic $\mathrm{T}$ lymphocyte-associated antigen 4," The Journal of Experimental Medicine, vol. 192, no. 2, pp. 303-310, 2000.

[32] S. Read, V. Malmstrom, and F. Powrie, "Cytotoxic T lymphocyte-associated antigen 4 plays an essential role in the function of $\mathrm{CD} 25^{+} \mathrm{CD} 4^{+}$regulatory cells that control intestinal inflammation," The Journal of Experimental Medicine, vol. 192, no. 2, pp. 295-302, 2000.

[33] K. Wing, Y. Onishi, P. Prieto-Martin et al., "CTLA-4 control over Foxp3+ regulatory T cell function," Science, vol. 322, no. 5899, pp. 271-275, 2008.

[34] X. B. Wang, M. Kakoulidou, R. Giscombe et al., "Abnormal expression of CTLA-4 by $\mathrm{T}$ cells from patients with myasthenia gravis: effect of an AT-rich gene sequence," Journal of Neuroimmunology, vol. 130, no. 1-2, pp. 224232, 2002.

[35] M. Gu, M. Kakoulidou, R. Giscombe et al., "Identification of CTLA-4 isoforms produced by alternative splicing and their association with myasthenia gravis," Clinical Immunology, vol. 128, no. 3, pp. 374-381, 2008.

[36] M. Alabdali, C. Barnett, H. Katzberg, A. Breiner, and V. Bril, "Intravenous immunoglobulin as treatment for myasthenia gravis: current evidence and outcomes," Expert Review of Clinical Immunology, vol. 10, no. 12, pp. 16591665, 2014.
[37] D. B. Sanders and G. I. Wolfe, "Developing treatment guidelines for myasthenia gravis," Annals of the New York Academy of Sciences, vol. 1412, no. 1, pp. 95-101, 2018.

[38] A. Jaretzki 3rd, R. J. Barohn, R. M. Ernstoff et al., "Myasthenia gravis: recommendations for clinical research standards. Task force of the Medical Scientific Advisory Board of the Myasthenia Gravis Foundation of America," Neurology, vol. 55, no. 1, pp. 16-23, 2000.

[39] J. Cui, W. Xu, J. Chen et al., "M2 polarization of macrophages facilitates arsenic-induced cell transformation of lung epithelial cells," Oncotarget, vol. 8, no. 13, pp. 2139821409, 2017.

[40] A. P. Cribbs, A. Kennedy, H. Penn et al., "Treg cell function in rheumatoid arthritis is compromised by ctla- 4 promoter methylation resulting in a failure to activate the indoleamine 2,3-dioxygenase pathway," Arthritis \& Rheumatology, vol. 66, no. 9, pp. 2344-2354, 2014.

[41] Y. Kumaki, M. Oda, and M. Okano, "QUMA: quantification tool for methylation analysis," Nucleic Acids Research, vol. 36, pp. W170-W175, 2008.

[42] J. Cui, Y. Yang, H. Li et al., "MiR-873 regulates ER $\alpha$ transcriptional activity and tamoxifen resistance via targeting CDK3 in breast cancer cells," Oncogene, vol. 34, no. 30, pp. 3895-3907, 2015.

[43] H. M. Gibson, C. J. Hedgcock, B. M. Aufiero et al., "Induction of theCTLA-4Gene in human lymphocytes is dependent on NFAT binding the proximal promoter," Journal of Immunology, vol. 179, no. 6, pp. 3831-3840, 2007.

[44] H. Yoshikawa, K. Satoh, Y. Yasukawa, and M. Yamada, "Cytokine secretion by peripheral blood mononuclear cells in myasthenia gravis," Journal of Clinical Neuroscience, vol. 9, no. 2, pp. 133-136, 2002.

[45] J. Trinath, P. Hegde, M. Sharma et al., "Intravenous immunoglobulin expands regulatory $\mathrm{T}$ cells via induction of cyclooxygenase-2-dependent prostaglandin E2 in human dendritic cells," Blood, vol. 122, no. 8, pp. 1419-1427, 2013.

[46] B. Richardson, "DNA methylation and autoimmune disease," Clinical Immunology, vol. 109, no. 1, pp. 72-79, 2003.

[47] K. Klocke, S. Sakaguchi, R. Holmdahl, and K. Wing, "Induction of autoimmune disease by deletion of CTLA-4 in mice in adulthood," Proceedings of the National Academy of Sciences of the United States of America, vol. 113, no. 17, pp. E2383E2392, 2016.

[48] L. Sun, Y. Meng, Y. Xie et al., "CTLA4 variants and haplotype contribute genetic susceptibility to myasthenia gravis in northern Chinese population," PLoS One, vol. 9, no. 7, article e101986, 2014.

[49] M. Fernandez-Mestre, K. Sanchez, O. Balbas et al., "Influence of CTLA-4 gene polymorphism in autoimmune and infectious diseases," Human Immunology, vol. 70, no. 7, pp. 532-535, 2009.

[50] X. B. Wang, R. Pirskanen, R. Giscombe, and A. K. Lefvert, "Two SNPs in the promoter region of the CTLA-4 gene affect binding of transcription factors and are associated with human myasthenia gravis," Journal of Internal Medicine, vol. 263, no. 1, pp. 61-69, 2008.

[51] D. J. Kim, S. K. Lee, J. Y. Kim et al., "Intravenous immunoglobulin G modulates peripheral blood Th17 and Foxp3(+) regulatory $\mathrm{T}$ cells in pregnant women with recurrent pregnancy loss," American Journal of Reproductive Immunology, vol. 71, no. 5, pp. 441-450, 2014. 
[52] L. S. Walker, "Treg and CTLA-4: two intertwining pathways to immune tolerance," Journal of Autoimmunity, vol. 45, pp. 4957, 2013.

[53] K. Klocke, R. Holmdahl, and K. Wing, “CTLA-4 expressed by $\mathrm{FOXP}^{+}$regulatory T cells prevents inflammatory tissue attack and not T-cell priming in arthritis," Immunology, vol. 152, no. 1, pp. 125-137, 2017.

[54] T. K. Fang, C. J. Yan, and J. Du, "CTLA-4 methylation regulates the pathogenesis of myasthenia gravis and the expression of related cytokines," Medicine, vol. 97, no. 18, article e0620, 2018.

[55] S. C. Li, W. C. Chan, Y. H. Huang et al., "Major methylation alterations on the $\mathrm{CpG}$ markers of inflammatory immune associated genes after IVIG treatment in Kawasaki disease," BMC Medical Genomics, vol. 9, article 37, 2016. 